Article

\title{
Illness Narratives and Facebook: Living Illness Well
}

\author{
Katrina Hinson * and Ben Sword * \\ Department of English and Languages, Tarleton State University, Stephenville, TX 76401, USA \\ * Correspondence: khinson@tarleton.edu (K.H.); sword@tarleton.edu (B.S.)
}

Received: 21 February 2019; Accepted: 21 May 2019; Published: 30 May 2019

\begin{abstract}
Earlier scholarship provides important insights into the relationship of individual stories and narratives. Interactions with healthcare professionals and the healthcare system can often subsume the individual's authority/agency. The patient's narrative often gets lost in the elaborate web of doctor visits, referrals, medical records, case notes, etc. Online spaces such as Facebook, however, provide individuals with a platform through which they can understand, craft, and communicate their own personal illness narratives. Realizing this, this paper examines how the narratives of illness shared in illness-related Facebook groups help individuals make sense out of the disruption caused by their personal experience while residing in the 'kingdom of the ill.' To observe the construction and communication of these narratives, the researchers observed the activity of an online pulmonary embolism and deep-vein thrombosis survivor support group for one year. In this online space, individuals gained agency and authority in the construction of their own illness narratives. The findings of the research demonstrated both the importance of narrative in an individual's health/illness journey as well as the need to further explore avenues that establish and bolster patient agency within the medical system.
\end{abstract}

Keywords: illness; narrative; social media; Facebook; storytelling; social networks; healthcare; health; medicine; digital

\section{Introduction}

Narrative and storytelling are mutable and often combine a variety of modalities and voices in a single event or become a single event told by multiple storytellers who have the common aim to inform, to entertain, to persuade, to build communal bonds, to strengthen relationships, to preserve self or to heal (Jaworksi and Coupland 2008, p. 25). Narrative has a privileged place over story because story may lack plot and coherence and embodies a certain familiarity and closeness not evidenced in the more formal structured narrative (Boje 2001, p. 1). Indirectly, the difference between narrative and storytelling is an implied difference in that narratives [not stories] are linear and temporally ordered. If any distinction could be made, it is perhaps in understanding that individuals' stories or episodes are told to create, advance, forward, or develop a master life narrative or life-story. Narrative thus becomes a collection of stories told over time that represent 'self' in and across various spaces. Understood this way, the narrative, the "performative domain of social action" (Edwards 2008, p. 227) is the whole of an individual's life while 'stories' represent the often informal and uncontrollable episodes of that life as individuals attempt to bring order to chaos. Ochs and Capps (2001) posit that narrative is complex and "contains some or all of the following discourse components: description, chronology, evaluation and explanation" (18). For one who is ill, the telling of one's illness story is a means through which individuals can "piece together their experiences" (Ochs 2004, p. 269) as they process what has happened or is happening, or may happen in the future. Willsey (2015) quotes psychologist Richard McNally writing "We all do this: We cast our lives in terms of narratives that help us understand them" (226). The telling of the illness narrative in the Facebook group, for some, brings understanding but for 
others, is a means to confront the stigma or shame associated with being one who is labeled chronically ill, disabled, or 'othered' in some form by their illness experience. These are individuals "who find themselves disqualified from whatever has been determined 'normal'" (Goldstein and Shuman 2012, p. 149) who now seek new footing, a new 'normal.'

As storytellers, folklorists are perhaps positioned well to capture the social lives of stories, including those stories of illnesses (HIV/AIDS, diabetes, chronic fatigue syndrome and others that carry a sense of stigma and shame) that have embedded in them the narrative of patients (Briggs 2012; Briggs and Mantini-Briggs 2003; Goldstein 2004). Goldstein (2004) writes "the narrative informs the listener in ways that not only affect thinking but also becomes enacted as the listener expresses belief or concern" (24). Virtual support groups created through social networking sites such as Facebook may help legitimate the illness experience for the individual and his or her family and give voice to those who would be silenced because of the stigmatization associated with their illness experience.

Physicians try to respect an individual's "ethic of voice" and the individual's "right to speak her own truth in her own words" (Frank 1995) but the individual affected, in the moment of an event, may feel unheard, ignored, or even dismissed. Physicians give priority to the science of medicine "rather than to the words and perceptions of the people they study," the patient. (Goldstein and Shuman 2012, p. 116). Participation in the group, the sharing of one's illness experience, privileges the story of the teller; the layperson's lived experiences more than the experts' science of medicine. However, the telling of a narrative also involves taking risks; the risk of not being heard and the risk of being 'othered' by "narratives [that] can also alienate, misrepresent, and create distance rather than cohesion" (Willsey 2015, p. 2018). The narratives in the Facebook group are "dialogic and interreliant-the experience being shared is the one created within the story, where teller and audience alike meet" (Willsey 2015, p. 218) but rather than "vicariously relive the past" as Willsey states, teller and audience are living out the present, the here and now of their illness experience, in addition to the past. Facebook illness groups allow for a somewhat constant dialogue between multiple tellers telling not just their own story, but shaping and developing the stories of others. This paper examines how the narratives of illness shared in illness-related Facebook groups help individuals make sense out of the disruption caused by their personal experience while residing in the 'kingdom of the ill.'

\section{Literature Review}

Stories are the (re)enactment of "important aspects of our identities and relations to others," which compose the narrative of self (Jaworksi and Coupland 2008, p. 27). The illness-narrative, then, becomes a sub-genre of narrative, as illness events are told and retold through the lens of the sufferers or those who have had to share the suffering of another.

Goffman's (1974) definition of narrative - "a tale or anecdote, that is, a replaying ... of a past event ... the personal perspective of an actual or potential participant ... [that is also] something that listeners [readers] can empathetically insert themselves and vicariously (re) experience what took place" (504) - is evidenced in the postings that occur in virtual support groups formed through Facebook. The illness narrative developed within the framework of a social media outlet is a distinct form of narrative, "distinct from say, a sermon, lecture, scientific explanation or any other discursive category" (Edwards 2008, p. 229). Like other narrative forms, illness narratives "(1) value an end point or goal, (2) an ordering of events (3) stable identities, (4) causal links and explained outcomes, and (5) demarcation signs marking the beginning and ending" (Edwards 2008, p. 228). The illness narrative notes Kevin Murray (1989) is a category of narrative on par with comedy, tragedy, romance, satire, and irony, and shares a close association with irony in that illness narratives understand "that comedy, romance and tragedy are mere schemes of mortals to control experience: individuals are not so pure, nor is the social order so healthy" (quoted in Edwards 2008, p. 229). The illness narrative can at times be humorous, tragic, and ironic while still highlighting individual awareness of one's own mortality as well as heightening the awareness of the mortality of others through the shared experience of illness. 
Above all else, the illness narrative is a narrative of personal experience that is intimately tied to the individual and yet invites others into the experience through the telling (Ochs 2004, p. 268).

Boje (2001) states that "story is an account of incidents or events [while] narrative adds 'plot' and 'coherence' to the storyline" (1), and that narrative comes after story and provides plot and coherence. Boje goes even further, developing a new term that he refers to as the antenarrative, "the fragmented, non-linear, incoherent, collective, unplotted, and improper storytelling" (1), which may more accurately describe what often happens in Facebook groups developed around illness. Whether fragmented, nonlinear, or at times incoherent, these Facebook groups become a means by which individuals tell their illness story and live out, or through, their illness experience(s). Sontag (1978) noted in Illness as Metaphor that "everyone who is born holds dual citizenship in the kingdom of the well and in the kingdom of the sick [and] sooner or later each of us is obliged, at least for a spell, to identify ourselves as citizens of the other" (3). For individuals who seek out and join a Facebook group related to their sojourn in the 'kingdom of the sick,' their membership in these groups allows participants to be 'sick' within the confines of virtual space even if they are unable to fully express sickness/illness when in the 'kingdom of the well.' Individuals can exist simultaneously in both but may feel they truly only belong, or 'fit in' with one. In the telling of his or her story, "the ill person who turns illness into story, transforms fate into experience; the disease that sets the body apart from others, in the story, becomes the common bond of suffering that joins bodies in their shared vulnerability" (Frank 1995, p. i). Illness narratives posted in virtual space allow for the enactment of Burke's (1969) theory of identification and consubstantiation, whereby illness becomes the common space of identification for those who would otherwise have nothing in common (Rhetoric, 20). The illness-related Facebook support group creates a space through which the individual becomes the narrator, the storyteller of his or her own illness story, in order to inform, to persuade, to heal those who also share the same illness experience. The story in turn becomes intertwined and developed over time both by the teller and those who respond, then becoming a narrative that has the power to transform. Though an individual has the choice to lurk or the choice/chance to speak, these spaces allow for, and even encourage, the interaction between many. The ill person, the wounded, in the sharing of his or her story within the group, becomes the narrator of his or her narrative, regaining a voice that may have been previously and unwittingly usurped by the healthcare professional.

Illness narratives are a form of health care that "recognizes suffering provides comfort and honors the stories of illness" (Charon 2006, p. 17), whereas the narrative that is heard and retold by the physician is based on the physician's interpretation of what a person has reported to him or her as well as what the physician has witnessed or observed that remained unspoken by the individual. The exam room silences many individuals who are "wounded not just in body but in voice" (Frank 1995). Although told by the individual, the medical record is the clinical record of the individual as interpreted or translated by the physician and transcribed often by some unknown other. Danish medical informatics researchers, Dr. Troels Mønsted et al. (2011), write about medical records, stating:

These documents have a strong narrative aspect because narratives supply a workable medium for representing knowledge that is time- and context- dependent-and often uncertain or ambiguous as well. They are created to organize, record, and capture practical experience (81).

Additionally, according to Mønsted et al., "a medical record embodies multiple intertwined representations of the patient" (81). But, the personal 'story' is subsumed, surrendered to the business of medicine (Frank 1995, p. 7). Sacks (1984), noted neurologist and author writes of the case notes:

tell[s] us nothing about the individual and his history; ... nothing of the person, the experience of the person as he faces, and struggles to survive his disease. There is no 'subject' in a narrow case history; ... To restore the human subject as the center-the suffering, afflicted, fighting subject - we must deepen case history to a narrative or tale; only then do we have a 'who' as well as a 'what', a real person, a patient, in relation to disease [or disorder]" (p. vii). 
The physician-centered narrative created by health care professionals revolves around a person's symptoms and diagnosis, but it may never tell the whole story from the individual's point of view. A person can be reduced, anonymized, to nothing more than clinical notations of symptoms and billing codes.

Those who find themselves lingering in the "kingdom of the ill" need to become storytellers or narrators "to recover the voice that illness has taken away" (Frank 1995, p. 44). Facebook groups related to illness allow for, even encourage the interactions between many and are spaces which privilege anecdotal knowledge of lived experience that otherwise might remain silenced. Illness narratives developed through Facebook groups advance understanding of the lived day-to-day experiences of people living with particular illnesses and diagnoses that may be lacking in the more traditional healthcare setting, especially when the individual's lived experience does not fit medical protocols.

The illness story developed within the Facebook group is also shaped by the stories of others. This 'storytelling' of the patient-created narrative empowers and enables patients to become more proactively involved in self-care management and illness prevention and awareness. The multiple 'stories' of one person's narrative may affect the choices another person may make while also providing a certain amount of legitimacy to the illness experience that might be otherwise stigmatized. Patients become "actors and agents creatively making sense of their illness" (Kangas 2002, p. 303). Hurwitz and Bates (2016) write "the passivity that so frequently accompanies severe illness is made all the more profound as a result of the language to which patienthood is subjected by modern healthcare ... that threaten[s] to eclipse the communal language of the lifeworld, the everyday concerns of bodily and psychic experience" (568). Facebook illness groups allow those who "feel misunderstood by the mainstream health service, those who seek to reformulate their experience" a medium through which to communicate just such experiences. (568). For the ill, illness becomes inseparable from the individual's master life-narrative.

Frank (1995) writes of the patients' loss of voice explaining, "In post-modern times, pressures of clinical practice, including the cost of physician's time and even greater use of technologies, less time is available for patients to speak" (15). In an article about the decline of the doctor-patient relationship, Elizabeth DeVita (1995) writes, "ask just about anybody and you will hear a doctor-patient horror story, a tale that reflects the indignation with which American's have come to view their healers" (63). Arthur Kleinman (1988), in The Illness Narratives writes, "the care of chronic illness is not one of the great success stories of contemporary medicine" (loc 143 of 5441, preface). Kleinman believes that modern medicine is flawed because "one intended outcome of modern medicine is that it does just about everything to drive the practitioner's attention away from the experience of illness ... to the alienation of the chronically ill ..." (loc 135 of 5441). Patients and physicians enter into an implied contract determined and controlled by each other's role expectations. (Beisecker 1990, p. 108). When those role expectations are challenged, conflict between doctor and patient can arise. One perhaps unintended result of the co-constructed illness narratives created through the medium of Facebook is that members, in the sharing of their personal narrative, and in the reading of one another's narratives, develop a language with which to challenge the expected physician/patient role boundaries. Chronic illness narratives are a means to reclaim the patient voice, to make sense out of the chaos of life (Charmaz 1990, p. 1161) and virtual support groups provide a vehicle by which otherwise silent stories, autobiographical narratives, can be expressed in such a way as to "preserve face" and to manage "potentially spoiled identities" (Goffman 1963, p. 80). Illness narratives are a means by which participants negotiate how they want to be known within their own illness narrative as well as the narrative develop collaboratively within the virtual support group and are a means by which individuals can shape their life with illness outside the context of the virtual support group.

\section{Research in Online Spaces}

Research in online spaces is relatively new and is constantly changing. The individual's daily lived experiences are now carried out or cross over into these online spaces, especially with the widespread 
use of social media outlets like Facebook. Online researchers, regardless of discipline-whether social science, linguistics, communication, or technical and professional writing - have had to adapt and modify existing methodologies for use in the online space as well adapt a variety of theories, based on the researcher's discipline, to these online research practices. Methods used to study online environments entail a certain amount of uncertainty; even if much anecdotal evidence identifies the value of virtual space, there is as noted much "uncertainty about how, or even if they can be evaluated in accordance with the clinical standards of evidenced-based [traditional] medicine" (Eysenbach and Till 2001, p. 20). But social media such as Facebook is "after all a social phenomenon [which] must be studied, at least in part, using tools and methods of social science" (Barker 2008, p. 20). Social science researchers often examine the relationship between the individual and the group to better understand how each produces and shares knowledge (Conrad and Barker 2010, p. S67). Such an approach, when applied to the study of medicine, has also been shaped by Goffman's (1961) work as a symbolic interactionist and his views on "patienthood." Symbolic interactionists believed that patienthood was "distinct from any biological condition ... [because] individuals actively participate in the construction of their own social worlds" (Conrad and Barker 2010, p. S68). Humans are, after all, social beings and when physical constraints like illness impede social interaction, Facebook groups, like those related to a certain illness or diagnosis, can lessen social isolation and create social interactions illness might otherwise prevent.

A social constructivist approach to illness "foregrounds how illness is shaped by social interactions, shared cultural traditions, shifting frameworks of knowledge and relationships of power" (Conrad and Barker 2010, p. S69). By sharing their illness narratives in Facebook groups, patients are constructing their own social world and constructing individual self-hood through ongoing interactions (S68). Virtual space may be the only place a chronically ill patient feels he or she is in control. An illness group can be viewed as a field that "reinforces specific social positions and power relations (Bourdieu 1986, p. 101). Members share their individual stories, symptoms, and treatment regimens, the habitus of their illness, in an effort of understand, to gain knowledge and have power over the illness rather than the illness controlling the patient's master narrative. The shared information of the illness group, the evolving master narrative of the illness, may move against expected medical discourse which, "constructs knowledge about the body including disease" (Conrad and Barker 2010, p. S68). The more the patient learns, the more he or she adjusts or modifies his or her own agency and the habitus in which he or she is a patient. Through storytelling, patients have the potential for their own transformative agency to affect not only their own health care, but also the quality of health care for others. As patients are actively involved in the decision-making processes of their care rather than maintaining a role of passivity and quiescence, they also have the potential to impact institutional practices and policies associated with their healthcare or the health care of others (Béhague et al. 2008, p. 491). Facebook illness group participants develop responses to their medical encounters, responses that are shaped not only by the patient's individual experiences or habitus, but also the experiences or habitus of others, thus creating a new form of social capital as yet unexplored. More importantly, the responses create a new patient narrative in which the patient is an active agent/actor rather than a passive actor that is acted upon. There is a redistribution of power within the doctor-patient relationship. The narrative within virtual space is a collection of fragmented, disjointed, non-sequential stories created simultaneously by the storytelling practices of multiple narrators and storytellers who then may use their new knowledge in encounters with their healthcare professionals.

A certain level of intimacy in the social constructivist approach lends itself to conducting fieldwork in the environment under investigation by immersing the researcher in the setting being studied (Barker 2008, p. 24). Illness-related virtual support groups are "organically occurring" and there is "much to be gained using methods that capture how they function day to day" (23). Although "field research (e.g., ethnographic, participant observation, or non-participant observation) can provide thick description of a natural social environment (24), there are, of course, ethical concerns related to whether the researcher should or should not disclose his or her presence in the setting being studied 
(24). The decision should be carefully made after weighing the risks involved. If the researcher is an active participant in the group from which research data will come, he or she must also consider the relationship of trust that has been established and decide whether or not he or she is going to risk that relationship in order to conduct the necessary research.

Another consideration is that if the researcher chooses to participate, "the online researcher [may] fundamentally change the peer to peer environment" (24). This consideration also assumes that the researcher does not naturally "belong" and overlooks the fact that the researcher may also be a patient-participant within the setting being studied. There is little evidence available that discusses whether patient-participant-researcher observation does or does not alter the research setting's content and structure (24). Additionally, online researchers contend with the issue of public versus private information and should do everything in their power to gain informed consent while maintaining subject anonymity. The argument can be made that once information is posted online, the individual forfeits any privacy; in contrast, the argument can also be made that a reasonable expectation of privacy be maintained, especially within group discussions (24). One way to address this sensitive ethical concern is to establish a collaborative relationship between the researcher and the community in which one wishes to collect data and build trust by being as transparent as possible. Ethnographic methodology affords a researcher a way to collaborate, build trust, and maintain transparency.

Ethnographic observation as applied and utilized in the social sciences needs to be modified for online research. Denzin and Lincoln (2005) demonstrate how ethnographic practices have been modified to work with online spaces, arguing that "computer-mediated construction of self and social structure constitutes a unique phenomenon of study" (646). Computer-mediated construction of self is made more unique as we consider that the virtual self does not have to be ill, even if the physical self is. Individuals could create a healthy virtual self when they log onto social media sites like Facebook; but the ill self is clearly evidenced by the large number of illness groups available via Facebook. These groups are more patient-driven than those created by health care professionals ( $\left.\mathrm{HCP}^{\prime} \mathrm{s}\right)$. Virtual illness groups coalesce "out of a particular intersection of forces, discourses and institutions" (Denzin and Lincoln 2005, p. 647) and in a manner become a genealogy that "maps the complex contradictory ways in which forces and processes come together to produce a certain set of effects ... they are histories of effects of consequences" (647). According to Peräkylä (2005), "many scholars working with written text have drawn insights and inspiration from the work of Michel Foucault" (871) and because he provided no definite method for textual analysis, for subsequent scholars, "a primary concern is ... how a set of 'statements' comes to constitute objects and subjects" (871). To illustrate the effective use of Foucauldian analysis, Peräkylä references Armstrong's application of Foucauldian methods to a study of how "rules defining the difference between dangerous and safe or between pure and dirty, have changed during the past two centuries ... Armstrong explored the evolution of the spaces in which individual identity is located" (871). Armstrong believed that "texts and practices are inseparable ... texts in question act as guidelines, instructions even, for actual social practices" (quoted in Peräkylä 2005, p. 872). A Foucaultian (1973) approach to text generated by the participants in the virtual groups might first consider how the groups are formed (archeology), secondly, explore the relationships built (genealogy), and third, determine how the groups impact care of self.

Care of self unfolds within the illness groups on Facebook. Foucault's (1973) work in The Birth of the Clinic emphasizes the way medical knowledge had, at the time of its writing, become a space of power, power that was often used to inappropriately label the "normal" and the "abnormal" and the ways such labels would adversely affect the individual. Today, individuals are labeled in a variety of ways, such as sick, ill, well, unwell, able, or disabled. Such labels need to be deconstructed: each individual's venture into what Sontag (1978) refers to as the "kingdom of the ill" (3) is different and the landscape is created by the words written and shared by the individual participant in the group. As the individual writes out his or her experience in the "kingdom of the ill," he or she is also forced to encounter his or her understanding of their label—sick, well, able, disabled, bereaved, or even victorious. The illness-related groups constructed through social media may give the individual the 
power to deconstruct his or her illness and to resist the label of being ill and may provide a means for the patient to live illness well.

Participants in virtual support groups are collectively shaping a new discourse, "writing seen from the point of view of the beliefs, values, and categories which it embodies ... a way of looking at the world" (Mills 2004, p. 5). Prior to the impact of observable 'data,' the patient and his or her story were central to physician's mode of care and social media reminds us of the importance of social interaction and the role social interaction can have on self-care. Illness narratives are a discourse of multiple utterances "which are regulated in some way and which seem to have coherence and force to them in common (6). For Foucault, medical discourse (illness narratives) shapes how an individual understands both the body and the body in relationship to illness. Because virtual support groups and social media have the potential to modify how patients perceive their condition, manage their illness, and communicate within the doctor-patient relationship, the narrative stories told in virtual space need to be examined if we are to fully understand how that discourse shapes the illness experience for individuals in relation to self and others, including health care professionals.

\section{Methodology}

The collection of data for narrative research can be wide and varied. Our approach for this project involved seeking and attaining approval for a long-term study which concluded in 2018, during which time one of the researchers was a participant observer within the group being studied. For this article, we've used a representative sampling of posts shared within the group to demonstrate how the posts act as stories or episodes that coalesce to form a larger narrative for both the individual and the group. The group selected is one of many on Facebook related to a particular illness event, in this instance, pulmonary embolism. The primary-researcher had experienced a pulmonary embolism and, through a previous research study while working on her $\mathrm{PhD}$, had an established rapport and a level of trust with the members of the group. As with any other research, one must be comfortable within the research site and be able to abide by established protocols of a given situation. Because the primary researcher was already an existing member, she understood the ebb and flow of day-to-day interactions and the etiquette of the group.

Unlike the prior study (Hinson 2014) which examined several groups over a 4-week time period, this study focuses on one group for a much longer time period, creating a larger corpus of data from which to work. A systematic search for Facebook support groups related to PEs and DVTs (deep vein thrombosis) was conducted utilizing the key words "pulmonary embolism," "DVTs" and "blood clot." The initial search yielded 239 such groups; 102 groups were excluded because they were non-English speaking or because they were related to non-blood clotting events (car shows, rock bands, etc.) leaving a potential 137 useable groups. However, 34 groups were omitted because they had a membership of 1 or fewer and showed no activity. Another 14 groups were removed because they were duplicates and 77 groups were removed because they had a membership fewer than 1000 . The majority of these 77 groups showed little to no activity with posts sporadically appearing and often not related to the actual illness event that forms the basis of this study. Several of the groups in the 77 excluded were 'memorial' groups dedicated in memory of someone who passed away and showed no activity after the initial dedication. This left 12 remaining groups with a membership between 1100 and 7900 individuals (see Table 1). Limiting the scope of the project to groups with more than 1000 members provided access to a large sample size. These 12 groups were listed as public, closed, or secret. In a public group, anyone can post and the information posted on the group's wall shows up in members' news feeds, which means people not in the group but on a member's friends list would still be able to see what is posted. In a closed or secret group, only the current or invited members of the group can see what is posted. For this project, we chose to look at the only open group in the top 12. 
Table 1. Facebook Pulmonary Groups by Size.

\begin{tabular}{lccc}
\hline \multicolumn{1}{c}{ Group Name } & \# of Members & Year Created & Type of Group \\
\hline Pulmonary Embolism Awareness (PEA) & 7814 & $2009+$ & Public \\
\hline DVT/PE/PTS/RVT & 3837 & 2015 & Closed \\
\hline Blood Clot Survivors & 3754 & 2014 & Closed \\
\hline Thrombosis Support & 3120 & $2012(?)$ & Closed \\
\hline Deep Vein Thrombosis Awareness & 2993 & 2007 & Closed \\
\hline Surviving a Silent Killer & 2711 & 2013 & Closed \\
\hline Pulmonary Embolism Awareness Project (PEAP) & 2231 & 2010 & Closed \\
\hline $\begin{array}{l}\text { Pulmonary Embolism, DVT, PTSD, Mental } \\
\text { Health Group Anonymous }\end{array}$ & 1963 & 2016 & Closed \\
\hline Pulmonary Embolism \& DVT Awareness UK & 1422 & 2013 & Closed \\
\hline DVT \& May-Thurner Syndrome Network & 1909 & 2010 & Closed \\
\hline Pulmonary Embolism Survivors & 1195 & $2009+$ & Closed \\
\hline
\end{tabular}

The Pulmonary Embolism Awareness (PEA) group ${ }^{1}$ has the largest membership base at 7,814 global participants (see Table 1 below). This membership represents a global 'slice' of PE/DVT survivorship including one of the researchers in this study; it is a public facing group and has 'awareness' as one of its stated group goals.

Additionally, because the PEA membership base is so large, membership overlaps with the membership in the other 11 groups.

After being granted approval for the study, we sought permission from the PEA group to use the data available, even though the design of the group as a public group to promote awareness could imply that consent was already tacitly provided in the group's description. An explanation of the study was posted to the group's main 'wall' page, with periodic reminders that the study was ongoing during the duration of the data collection period from September 2016 to July 2018. The reminders also served to alert new members who joined the group during that time frame of the research being done and helped maintain a level of trust between researchers and members in the group. It was very important to the researchers to be conscientious of an ethics of care associated with the still-unchartered space of Facebook as a research site and kept researchers mindful of the tensions between public and private when it comes to Facebook. Anyone in the group could opt out at any time and all information was de-identified as much as possible. Real names, exact locations, and any references to specific employers were not disclosed in this study. However, when shared on the group's wall, because of the nature of an 'open group,' we did opt to use photos (See Figure A3 part 5) as provided in the post because of the way in which such images add to the overall narrative.

The advantages of using Facebook as a research space is the sense of reciprocity. All the members in the public group could see posts shared on the groups wall. Those same posts also displayed in members' news feeds and were visible to a much wider audience than if the group were closed or secret. Participants had easy access to the researchers through direct message of Facebook messenger as well as by email or phone if needed. Facebook messenger is an affordance that definitely serves as a back channel of information during the observation period. Data collected through the Facebook group is far richer than that of a simple status update on a person's wall. Page (2012) states that "stories remain one of the most pervasive genres people use to make sense of themselves and the surrounding world" (xv). Add the element of social media which actively allows and encourages the storytelling of

1 Pulmonary Embolism Awareness Facebook Group, Retrieved from Jun 2016 through June 2018. Available online: https://www.facebook.com/groups/Pembolism/. 
the mundane and the serious and there is an even greater need to examine the impact of these stories in this space on the individual's master 'life narrative' as well as the sociocultural impact of a larger more nebulous 'society.' Additionally, the power of the anecdotal data related to specific illness events is, in and of itself, worthy of further study by diverse others when one considers that the illness narratives created through social media shape and extend an individual's illness experiences.

\section{Findings}

Research from this study demonstrates that users who have suffered a pulmonary embolism (PE), a deep vein thrombosis (DVT), or both form groups through Facebook because it affords them a space through which to vocalize their experiences (See Appendices A and B). Facebook is a place where individuals express their experiences with illness events and seek to come to terms with their experiences when traditional medical avenues fall short. Cameron Norman (2012) states "social media realizes [Edmund] Carpenter's vision by placing participation and co-production at its core" (4). Individuals are no longer simply talked to as in a lecture, but are rather invited to engage in the conversation(s). Facebook and its associated applications encourage this co-production and has changed the way in which individuals create and value knowledge. People use their social networks to organize information both on an individual and collective level in order to share similar experiences and gain new insight from persons with similar circumstances. Individuals who now have access to information in a larger, quicker capacity than ever before can exchange that information on a scale unlike anything society has previously experienced. Social media is to modern society what the printing press was to the Medieval Period. Technological advances related to social media increase the need for understanding how individuals now create social networks around health-related concerns that exist almost exclusively in virtual environments like Facebook.

Postings shared via the Facebook medium allow people to express their lived experiences (See Appendices A and B). Facebook postings, more than other social media, may share many of the same features of narrative-storytelling in which the speaker/narrator/storyteller demarcates the beginning and end of the 'story' or episode; events are sequenced to reveal an overall plot and involve the actions of characters (friends, family, co-workers and peers, significant others, healthcare professionals, ancillary healthcare service professionals, and diverse others) who are as much a part of the narrative being told and retold as the narrator-storyteller. Posts shared on an illness group's wall are often (not always) more developed than what might occur naturally in conversation and evoke a certain shared empathy. Acknowledging the common bond between storytelling and research, Riessman (1993) states, "Storytelling, to put it simply, is what we do with research and clinical materials, and what informants [participants] do with us ... [the story/narrative] does not assume objectivity, but, instead privileges positionality and subjectivity" (Narrative, 3). Illness is a disruption in an individual's master narrative or life story and it fundamentally alters the individual (Riessman 2003, Analysis, p. 332). Illness may be a one-time disruption, or as with chronic illness, may be an ongoing disruption marked by various episodes that flare and resolve from onset of illness to either cure, repair/restoration, or death is achieved. The discourse created by individuals who seek out and join illness-related Facebook support groups is not only shared but also shaped and reshaped by responses to the story.

Narratives from within the virtual support group share many of the same characteristics as any other narrative. If a narrative is, as Charon noted, a clinical cousin of literature, the implication is that the narratives created in virtual space are likewise structured (Charon 2006). Individually, we are always engaged in an ongoing process of creating small stories of the life lived; virtual space is an extension of that life space, even if only peripherally. Bamberg and Georgakopoulou (2008) identify what they call "small stories," narratives which exist on the fringe (379). Illness narratives in virtual space may exist on the fringe but "they can be used as a point of entry into identity analysis ... privileged forms/structures/systems for making sense of self ..." (378). The history of narrative and narrative as research from varied disciplines (Propp 1928; Labov and Waletzky 1967; Labov 2008; Bakhtin 2010; Ochs and Capps 2001; Ochs 2004; Bold 2012) establishes a foundation from which to 
explore the contemporary text created via the Facebook medium, as narratives, more precisely the narratives in Facebook illness groups as illness narratives/pathographies.

Kleinman (1988) writes of illness as a 'biological disruption' experienced by the patient:

"Thus patients order their experience of illness-what it means to them and to significant others-as personal narratives. The illness narrative is a story the patient tells, and significant others retell, to give coherence to the distinctive events and long-term course of suffering. The plot lines, core metaphors, and rhetorical devices that structure the illness narrative are drawn from cultural and personal models for arranging experiences in meaningful ways for effectively communicating those meanings" (49-50).

The illness narrative within a virtual support group such as those found through Facebook can be identified by the beginning, usually marked by the onset of illness, and then marked again by entrance into the virtual support group. These stories "are stories of marginality from a perspective not present in expert [physician-centered] views" (Kangas 2002, p. 303). The telling of one's illness narrative in these illness-related Facebook groups invites others to share the illness experience, thus creating a new co-constructed narrative.

Participants within the illness-related Facebook group coalesce around critical health care phenomena. Their shared virtual patient illness narratives not only help them make sense of their illness/diagnosis but may also influence their understanding of "good or bad" health care professionals (Peters and Gillett 2012, p. 2), the type of healthcare to seek out, and when to seek it out. Furthermore, the illness narratives also function as a means of teaching individual self-advocacy and educating one another in ways that may provide an individual with a more equal voice in the doctor-patient dyad, layperson-expert dyad. Lastly, these narratives provide a shared empathic experience needed for improved adherence to treatment plans and better patient self-care practices. Unlike a face-to-face group aligned with a specific illness that may meet with a facilitator, virtual spaces may have no facilitator as such, no set time or day in which the virtual group 'meets.' The group is fluid and organic, always on and rarely, if ever, off. Rita Charon (2006) writes "patients have found new allies in their search for health, notably in advocacy groups and support groups, in the readership of published and electronic 'telling of illness stories'" (ix). The everyday stories of illness, of the struggles to live with and through illness, find form and voice in the co-constructed narrative of illness-related Facebook groups.

\section{Conclusions/Implications for Future Research}

The role of narrative in relation to health/illness and medicine has historically fluctuated in importance (Laqueur 1989; Hess and Mendelsohn 2010; Hurwitz and Bates 2016; Frank 1995; Kleinman 1988; Charon 2006), beginning as a somewhat accepted element of case study only to be supplanted by the observable data yielded as medical instruments were developed and then once more returning as part of the physician/patient encounter as patient advocacy groups in the mid- to late-twentieth century pushed the importance of narrative. Sikes and Gale write "Human beings are storying creatures. We make sense of the world and the things that happen to us by constructing narratives to explain and interpret events both to ourselves and to other people" (Sikes and Gale 2006). Although Facebook is a rather new medium through which to consider the illness narrative, it is a medium that is indelibly linked to the stories people tell every day, whether detailed and full of thick description or representations of the mundane and ordinary. In the illness-related Facebook groups, members have a chance to voice their own experiences with illness and listen to and validate the illness experiences of others. Davies (2015) writes "It is through cultural materials that we voice our stories and if these stories are not shared, then the story cannot be made manifest" (6). Whether a story is told for the sake of the story or with some grander 'point' or purpose in mind, the collection of stories are the moments of our lives. When that life is disrupted by, interrupted by illness, the telling and re-telling of the story can be a restorative pathway back to health even if that pathway is an acceptance of illness as part of one's life-narrative. Social interactions surround us, evidenced more and more frequently through 
our social interactions in online spaces like Facebook; as we tell our own narrative, respond to the illness narrative of others, and retell our own as our illness journey advances, the narrative created can demystify the often unexpected interruptions caused by illness.

Author Contributions: Conceptualization, K.H. and B.S.; Formal analysis, K.H. and B.S.; Investigation, K.H. and B.S.; Methodology, K.H. and B.S.; Project administration, K.H.; Writing-original draft, K.H. and B.S.; Writing-review \& editing, K.H. and B.S.

Funding: This research received no external funding.

Conflicts of Interest: The authors declare no conflict of interest.

Appendix A. Member Post 20161030P9

20161030P9

Thank you for adding me to the group, at the moment I think I'm still in shock with the diagnosis of a pulmonary embolism on the 21st of this month. I had went in to hospital on the 19th for a routine operation which went straight forward, apart from 2 fainting episodes recovering from the anaesthetic. I returned home but started having breathing difficulties on the Thursday evening. I was putting it down to the tubes being down my throat during the operation but by the early hours of the Friday morning I knew something wasn't right.

I phoned my local clinic to see my GP but within minutes of examining me she asked me to go straight to hospital and she phoned ahead to expect me.

Everything happened so fast x-rays, blood work, ECG then CT scan. Then the bomb shell that I had a pulmonary embolism.

I've been put on Eliquis apixaban which the consultant thinks will be for life as family history of clots and the fact that I had a clot in my left leg in Dec12 and my right leg July 15 ( both after long haul flight) which where treated with heparin injections.

I'm scared for the future, being dependent on a drug and having restrictions on my life. So my questions going through my head which at the moment doesn't help with my breathing and racing heart rate, some down to the PE and the rest down to panic.

Can anyone tell me the recovery period for a PE? Still struggling with breathing and climbing stairs etc.

Thank you for reading

(b) 3012 Comments

Figure A1. 20161030P9'S Original Post to PEA Facebook Group. 
- R1 You're as new to it as I am. Hope you get somer esponses $\mathrm{xxx}$

Like $\cdot$ Reply $\cdot 2 y$

R2 My husband and I are both on Eliquis. Hubby is for afte $r 1$ incident. Eliquis is the number 1 selling drug in Canada. Lowes $t$ bleeding rates to. Anyhow life on thinners forthubby hasn' $t$ changed things too much. He was on life supportso he sees th e meds as a fare trade for life. Recovery is edocument ed as 1-2 years. Although for many they recover before then.. I run a group called ... Pulmonary embolism dvt ptsd mental health anonomous in this group is have alot of articles posted on what recovery looks like.

Like $\cdot$ Reply $\cdot 2 y$

R2.1 My husband had a Massive bilateral PE॰and Massive bilate ral DVT 100 clots in his lungs completely covered. As I said $h$ e was on life support. Survived by miracleønly. He has a fe w complications in his legs mostly but otherthen tha t doing amazingly well!

Like $\cdot$ Reply $\cdot 2 y$

\section{R3 1. Welcome from just a few miles up theroast}

2. Your recovery will take as long as it takes ... we are all different in this. I still struggle with stairs on a bad day (two plus years after first PE) but as I am walking more and my lungs are reconditioning the good days are almost like I used to be. 3. Instead of seeing the anticoagulant as limiting what you can do thinking about it as the thing that allows you to live a pretty much normal life without more clots. I am on Rivaroxaban (works by the same mechanism as Apixaban and the only concession I give to what I do is to wear a medic alert bracelet.

4. You will have several trips to $A \& E$ or your doctor until you understand the signs of your own body

Like $\cdot$ Reply · $2 y$

Figure A2. Cont. 
R4 I'm amazed you didnt get put on a blood thinner-pos t op given yours and your families history of clots... pleaselist en to your body, it does take time and its different foreveryone ... one day you'll walk up the stairs and not notice being out of breath and you'll post on here and feel fantastic $\because$ keep* positive and welcome

Like | Reply - 2y · Edited

P9.1 I was given heparin injections and on my 3rd day ( they had planned for me to be taking them fo $r 7$ days post op) when diagnosed with the PE.

Like | Reply · $2 y$

R4.1 Oh I see.. glad you've found us Lik

e $\cdot$ Reply $\cdot 2 y$

Write a reply...

(-) 0 다 $\theta$

R5 I'd like to add that 叉ou're lucky to have GP who diagnosed you so quickly! Many of our members'suffered numerous trips to doctors and ERs before being'correctly diagnosed. Just try to take your time and listen to the eues your body will give you. If you're tired, rest. As time goes by you'll begin to see improvement. Don't be surprised if you feel-anxious or nervous about repeat clotting. By all means, when it -doubt check it out! Most of the time it will be nothing but better safe than sorry. Good luck with your recovery.

Like: $:$ Reply · $2 y$

R6 Welcome, everyone is different and yourrecovery maybe frustrating as sometimes there's no pattern to it.Your body will recover though.

Like $\cdot$ Reply - $2 y$ Edited

R7 Im 4 months since diagnosis and i still strugglealot.. my legs are in pain all the time..good and bad days even॰now

Figure A2. Cont. 
R8 Lots of great support \& info on this page. I'm 2months post PEs \& feel pretty good now, just tire a bit quicker, l-went back to work about 3 weeks after. But like the others sayeveryone is different \& has a different story \& recovery process. Wishing you all the best

Like $\cdot$ Reply $\cdot 2 y$

R9 Hi, so glad you made it! I suffered PEs and•DVTs after surgery. It took me 6 months for clots in my body to disappear. Was on coumadin for just over 6 months. I am one-year past my hospitalization for the PE and I am fully recovered. lohave to take baby aspirin every day. Also have to have Lovonox-shots if I fly. Other than that I am good. Glad to be alive!

Like. Reply $\cdot 2 y$

R8.1 Can I please ask what doseage "baby"•aspirin is?

Like $\cdot$ Reply $\cdot 2 y$

R9.1 $81 \mathrm{mg}$-Like · Reply · $2 \mathrm{y}$

P9.2 - Thanks everyone for relying, it's much•appreciated. My main concern at the moment is recovery time as everything is an effort and leaves you so drained of energy. I'verto go for a scan on my heart in a few weeks to make sure no*damage has occurred then see the consultant in January, in the meantime l've to see my gp.

Like $\cdot$ Reply $\cdot 2 y$

Figure A2. Cont. 
- R1.2 I was exhausted yesterday, absolutely wiped•out but today I feel better altho I didn't get out of bed til 11am. I.gress it's going to be like this for a while $x$

Like - Reply - 2y

P9.3 How long has it been for you Jacky?Today I was determined to try and have a normal day butd've had to come and sit down and rest.

Like - Reply - $2 y$

- R1.2.1 Hospitalised 2 weeks ago tomorrow with•multibilateral PE. In hospital 4 days. Was off work last'week and now been signed off a further 2 weeks doesn'thelp that I'm having the period from hell which may be*contributing to the tiredness. $\mathrm{X}$

Like - Reply - $2 y$

P9.4 Do they know what the trigger was for you? I was in for an operation to remove scar tissue ${ }^{\circ}$ caused by previous clots in my legs, ironically removing the scar tissue was to reduce the chance of developing more clots

Like $\cdot$ Reply $\cdot 2 y$

- R1.2.2 No, unexplained so far but when in hospital the consultant said they were assuming it wasthe pill as all my other risk factors were low, no surgery or-recent flights, but I've got Polycystic Ovarian Syndromerso am booked in for a pelvic scan next month to check •there's nothing dodgy going on down there. My GP says॰they're wrong to assume it's the pill when they've noteven scanned my legs and that at my first appointmentol'm to push for more scans and to check for familial cause ${ }^{-1} \cdot$ Factor 5 Leiden. I'm exhausted one day but ok the next• but trying to take it easy even if I feel ok as doing too* much sets me back again. $X$

Like - Reply - $2 y$

Figure A2. Cont. 
P9.5 They took me off the pill years ago'because I was at risk with family history but it was a $12 \mathrm{hr}$ r light that caused my 1st in my left leg. All flight after that 1 would take $75 \mathrm{mg}$ of aspirin a week before and a week after to reduce my chances along with flight socks. Hopefully the get to the bottom of yours, more for peace of mind $x x$

Like $\cdot$ Reply $\cdot 2 y$

Figure A2. Responses to Figure A2.

\section{Appendix B. Member Post 20161030p11}

\section{P211}

Today is the day I class as my 1st clot Anniversary

It started with me waking up on the 28th October last year just feeling a little out of breath ( like I needed an inhaler )

Also a little anxious but I carried on with my day and went out in my car to do some chores.

Later that evening I felt something wasn't quite right and did a symptom checker on google, which kept flashing up ( call an ambulance urgently) but I laughed... I was feeling great apart from theses niggles!

But something told me to ring my GP for reassurance.

She asked me to get my husband to drive me there straight away so she could check me over.

My oxygen sats where $100 \%$ but my pulse was sky high, she checked me over and when she pressed on my chest/heart area I winced as it hurt? She checked my legs but all great!

I told her it's got to just be stress and anxiety as I had a big issue going on at home, that was eating me up with worry, she said "maybe Denise, it does sound like it but because your pulse is so high and your symptoms I' $m$ sending you up to the emergency unit so they can reassure me" I was laughing and joking with my daughter and her fiancé when I got there and waiting my test results, telling the Drs it's just anxiety I'm sure... but they all looked really serious ( which unnerved me slightly) Then I finally had a consultant come through and he told me "we believe you may have a little blood clot on your lung, but nothing to worry about, we'll start you on Fragmin injections straight away and we'll show you how to use them yourself before you go. We really need you to come in first thing in the morning, so we can give you a CT scan with contrast but you really MUST make sure you do"

I went home feeling really unnerved but trusted they must know it's something \& nothing.. 
I didn't sleep that night as I just couldn't get comfy my whole upper chest/back/shoulder area hurt.

So anyway... my mum \& daughter came with me whist I had the CT scan, even walking down there I thought "honestly this is a waste of time, its anxiety and if there was a tiny clot, it's probably gone by now" I went \& sat back with my mum/daughter thinking it would take hours for results, paying lots of attention to my daughter who was expecting my 1 st Grandchild and getting excited about it $\$$

Within 15mins I was called into the consultants office and I couldn't understand why he was looking So worried??

He made me sit down and pulled in close to me..."Denise, lastnight when we did your D-dimer test, it was off the rictor scale. So we knew you definitely had a clot but we didn't realise how serious it is. It's shocked us how bad it is.

Both your lungs are absolutely FULL of Clots and the biggest Clot is in the main right heart valve, putting immense strain on your heart. This is serious."

My head wasn't there, I felt like I was being given the death sentence and I just couldn't take it in. I asked if I was to die??

He told me that I have a long battle ahead of me but to continue with the fragmin injections and I could go home, but if I started to feel any worse then to come straight back to emergency.

I was obviously in a state of shock but I still didn't realise what all this Clot stuff was about???

I walked out and told my mum, who,s face said it all, she was crying. Again... I still didn't know what all the fuss was about as I felt well in myself? And if it was that serious then they wouldn't let me home. That evening was horrendous, I woke up at 4 am in a sweat feeling like I had an elephant sat on my chest and my anxiety was through the roof.. I'd got an appointment with my normal GP that day,about something else, my parents had to take me as the fever I had was awful and I kept wanting to black out. As soon as my GP saw me and I told her the results of the CT she looked absolutely horrified! and called an ambulance straight away, saying they should NEVER of let me go home. So back I go!

Figure A3. Cont. 
The consultant I first saw was there to greet me and ran more tests... my pulse was way too high but my oxygen sats were still $100 \%$. He said "I'm so glad you came back, we'll keep you in over the weekend for constant observation" It's was a relief for all of us...

I was put on a ward upstairs where the nurses could check on my obs monitor all night.

The next morning (a yr ago today)

I got up to use the bathroom and me ears started ringing walking back... I woke up on the floor having collapsed.

It was absolutely mayhem from then...I remember being back on the bed with a team around me working on me.

They were feeling my toes and hands and how cold they were, they all looked really worried? I started to panic as I couldn't swallow ( which really freaked me out)and my whole body was closing down on me ( although I didn't know that)

The trauma that followed still haunts me now 20

They called up the trauma team and everyone was frantically working on me as they rushed me to ICU.

All I could hear was "we're losing her"

When they got me to ICU they had to put in a central line ( because my body was so cold shutting down) and I remembered every single part of the pain from having it put in as they struggled even to put this in.

Then hearing them say "call her husband now, she hasn't got long left" They managed to stabilise me for a bit and told me they were bringing in my family to say goodbye.

Seeing them in a line at the door looking terrified was too much but I had to be brave for my 3kids especially. Everyone was allowed in 2 at a time. I was SO weak and could hardly talk, plus wires everywhere but I managed to say something that would mean something to each of them, it was a highly emotional Time for all of us $\$$ anyway the journey that followed was touch and go most days. Each day I survived it was a miracle A. I was also taken straight off lots of medications I'd been on for the last decade, so I was not only fighting for my life daily but also going through the most horrendous withdrawals. Everyday a few of my

Figure A3. Cont. 
friends would come in and pray for total healing and restoration, really believing it would happen! But I was convinced now I'd said goodbye to everyone it was my time to go home.

But God had other plans...

It's now a year later and not only was I told the Clots had ALL gone ( after another scare about 3months after) but I've not got one single bit of scarring anywhere and my heart is beautiful healthy, my body wasn't left

with any damage whatsoever 0 mentally unfortunately I have... I've been diagnosed with CPTSD. Which has been horrendous leading up to this date.

I've also got it hanging over my head that I'm high risk for it happening again anytime \& a lifer on Apixiban (Elequis) but I will keep fighting it and thanking God that I'm still here

Yesterday was such a special day for me... I got to have my 6 month old granddaughter over for her 1st sleepover with Nanna\%? one of the things that kept me fighting hard to stay alive was my daughter holding up the Doppler to my ear most days in ICU... and her telling me "listen Mum! She needs her Nanna, she needs you in her life" her heartbeat kept me fighting $\uparrow$ and yesterday as she fell asleep on me, our hearts beat beautifully together 6 it was a beautiful reminder that the fight was worth it! I now also have my 2nd grandchild on the way early next year with my younger daughter $\mathcal{C}$ This last year has been hellish ( as I have lots of other health issues on top) But just wanted to encourage anyone that feels like giving up..... hang in there..

Figure A3. Cont. 


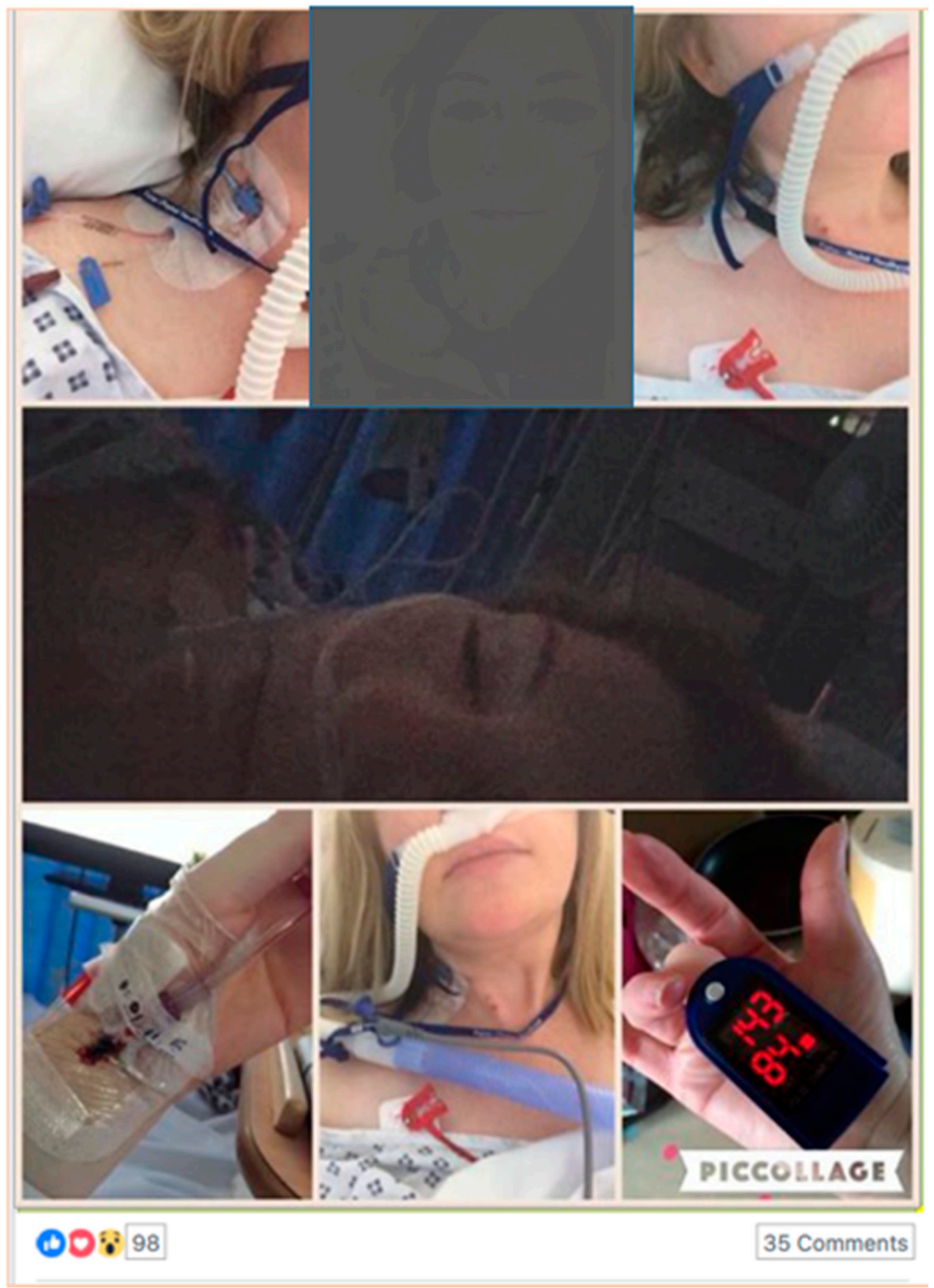

Figure A3. Member Post 20161030P11.

\section{References}

Bakhtin, Mikhail. 2010. Speech Genres and Other Late Essays. Austin: University of Texas Press.

Bamberg, Michael, and Alexandra Georgakopoulou. 2008. Small Stories as a New Perspective in Narrative and Identity Analysis. Text $\mathcal{E}$ Talk: An Interdisciplinary Journal of Language, Discourse $\mathcal{E}$ Communication Studies 28: 377-96. [CrossRef]

Barker, Kristin K. 2008. Electronic Support Groups, Patient-Consumers, and Medicalization: The Case of Contested Illness. Journal of Health and Social Behavior 49: 20-36. Available online: http://www.jstor.org.zeus.tarleton.edu: 82/stable/27638733 (accessed on 12 December 2013). 
Béhague, Dominique P., Lydie G. Kanhonou, Véronique Filippi, Solange Lègonou, and Carine Ronsmans. 2008. Pierre Bourdieu and Transformative Agency: A Study of How Patients in Benin Negotiate Blame and Accountability in the Context of Severe Obstetric Events. Sociology of Health E Illness 30: 489-510. [CrossRef]

Beisecker, Analee E. 1990. Patient Power in Doctor-Patient Communication: What Do We Know? Health Communication 2: 105. [CrossRef]

Boje, David. 2001. Narrative Methods for Organizational \& Communication Research. Thousand Oaks: SAGE.

Bold, Christine. 2012. Analyzing Narrative Data. In Using Narrative in Research. Thousand Oaks: SAGE.

Bourdieu, Pierre. 1986. The Forms of Capital. In Handbook of Theory of Research for the Sociology Foundation. Translated by Richard Nice. New York: Greenwood Press.

Briggs, Charles, and Clara Mantini-Briggs. 2003. Stories in the Time of Cholera: Racial Profiling during a Medical Nightmare. Los Angeles: University of California Press.

Briggs, Charles. 2012. Towards a New Folkloristics of Health. Journal of Folklore Research 49: 319. [CrossRef]

Burke, Kenneth. 1969. A Rhetoric of Motives. New York: Prentice Hall.

Charmaz, Kathy. 1990. Discovering Chronic Illness Using Grounded Theory. Social Science and Medicine 30: 1161-72. [CrossRef]

Charon, Rita. 2006. Narrative Medicine: Honoring the Stories of Illness, Kindle ed. New York: Oxford University Press.

Conrad, Peter, and Kristin Barker. 2010. The Social Construction of Illness: Key Insights and Policy Implications. Journal of Health and Social Behavior 51: S67-S79. [CrossRef]

Davies, Julia. 2015. Facebook narratives. In The Routledge Handbook of Literacy Studies. Edited by Jennifer Rowsell and Kate Pahl. London: Routeledge, pp. 396-409. [CrossRef]

Denzin, Norman, and Yvonna Lincoln. 2005. The Sage Handbook of Qualitative Research. Thousand Oaks: SAGE.

DeVita, Elizabeth. 1995. The Decline of the Doctor-Patient Relationship. American Health 14: 62-67.

Edwards, Derek. 2008. Narrative Analysis. In The Discourse Reader. Edited by Adam Jaworski and Nikolas Coupland. New York: Routledge, pp. 227-38.

Eysenbach, Gunther, and James Till. 2001. Ethical Issues in qualitative research on internet communities. BMJ 323: 1103-5. [CrossRef]

Foucault, Michel. 1973. The Birth of the Clinic, Kindle ed. Translated by Alan Sheridan Smith. Edited by Ronald D. Laing. New York: Pantheon Books.

Frank, Arthur. 1995. The Wounded Storyteller: Body Illness, and Ethics. Chicago: University of Chicago Press.

Goffman, Erving. 1961. Asylums: Essays on the Social Situation of Mental Patients and Other Inmates. New York: Anchor Books.

Goffman, Erving. 1963. Stigma: Notes on the Management of Spoiled Identity, Kindle ed. Upper Saddle River: Prentice Hall.

Goffman, Erving. 1974. Frame Analysis. Boston: Northwestern University Press.

Goldstein, Diane E. 2004. Once Upon A Virus: AIDS Legends and Vernacular Risk Perception. Logan: USU Press.

Goldstein, Diane E., and Amy Shuman. 2012. The stigmatized vernacular: Where reflexivity meets untellability. Journal of Folklore Research: An International Journal of Folklore and Ethnomusicology 49: 113-26. [CrossRef]

Hess, Volker, and Andrew Mendelsohn. 2010. Case and Series: Medical Knowledge and Paper Technology, 1600-900. History of Science 48: 287-314. [CrossRef]

Hinson, Katrina. 2014. Chronic Illness Narratives through Facebook. Ph.D. dissertation, East Carolina University, Greenville, NC, USA.

Hurwitz, Brian, and Victoria Bates. 2016. The Roots and Ramifications of Narrative in Modern Medicine. In The Edinburgh Companion to the Critical Medical Humanities. Edited by Angela Whitehead and Angela Woods. Edinburgh: Edinburgh University Press, pp. 559-76.

Jaworksi, Adam, and Nikolas Coupland, eds. 2008. Introduction: Perspectives on Discourse Analysis. In The Discourse Reader. New York: Routledge, pp. 2-37.

Kangas, Ilka. 2002. Lay and Expert: Illness Knowledge Constructions in the Sociology of Health and Illness. Health: An Interdisciplinary Journal for Social Study of Health, Illness and Medicine 6: 301-6. [CrossRef]

Kleinman, Arthur. 1988. The Illness Narratives: Suffering, Healing and the Human Condition, Kindle ed. New York: Basic Books.

Labov, William, and Joshua Waletzky. 1967. Narrative analysis: Oral Versions of Personal Experience. In Essays on the Verbal and Visual Arts: Proceedings of the 1966 Spring Meeting of the American Ethnological Society. Edited by June Helm. Seattle: University of Washington Press, pp. 12-44. 
Labov, William. 2008. The Transformation of Experience in Narrative. In The Discourse Reader. Edited by Adam Jaworski and Nikolas Coupland. New York: Routledge, pp. 218-26.

Laqueur, Thomas. 1989. Bodies, Details, and the Humanitarian Narrative. In The New Cultural History. Edited by Lynn Hunt. Berkeley: University of California Press, pp. 176-204.

Mills, Sara. 2004. Discourse. New York: Routledge.

Mønsted, Troels, Madhu C. Reddy, and Jørgen Bansler. 2011. The Use of Narratives in Medical Work: A Field Study of Physician-Patient Consultations. In ECSCW 2011: Proceedings of the 12th European Conference on Computer Supported Cooperative Work, Aarhus, Denmark, 24-28 September 2011. Edited by Susanne Bodker, Niels Olof Bouvin, Volker Wulf, Luigina Ciolfi and Wayne Lutters. Denmark: Springer, pp. 81-100.

Murray, Kevin. 1989. The Construction of Identity in the Narratives of Romance and Comedy. In Texts of Identity. Edited by John Shotter and Kenneth J. Gergen. London: SAGE, pp. 181-82.

Norman, Cameron D. 2012. Social Media and Health Promotion. Global Health Promotion 19: 3-6. [CrossRef] [PubMed]

Ochs, Elinor. 2004. Narrative lessons. In A Companion to Linguistic Anthropology. Edited by Alessandro Duranti. Malden: Blackwell, pp. 269-89.

Ochs, Elinor, and Lisa Capps. 2001. Living Narrative: Creating Lives in Everyday Storytelling. Cambridge: Harvard University Press.

Page, Ruth. 2012. Stories and Social Media: Identities and Interaction. New York: Routledge.

Peräkylä, Ansii. 2005. Analyzing Talk and Text. In The SAGE Handbook of Qualitative Research. Edited by Norman Lincoln and Yvonna Dennison. Thousand Oaks: SAGE, pp. 869-86.

Peters, Amanda, and James Gillett. 2012. Health Professional Narratives and the Patient: An Analysis of Meaning in Online Medical Blogs. Prague: Inter-Disciplinary.Net, pp. 1-12.

Propp, Vladmir. 1928. Fairy-Tale Transformations. In Narrative Dynamics: Essays on Time, Plot, Closure, and Frames. Edited by Brian Richardson. Columbus: Ohio State University Press, pp. 73-93.

Riessman, Catherine. 1993. Narrative Analysis. Thousand Oaks: SAGE.

Riessman, Catherine. 2003. Analysis of personal narratives. In Inside Interviewing: New Lenses, New Concerns. Edited by James Holstein and Jaber Gubrium. Thousand Oaks: SAGE, pp. 331-46.

Sacks, O. 1984. A Leg to Stand On. New York: Touchstone.

Sikes, Pat, and Ken Gale. 2006. Introduction. RESINED: Narrative Approaches to Educational Research. Sontag, S. 1978. Illness as Metaphor. New York: Farrar, Straus and Girouy.

Willsey, Kristiana. 2015. Falling Out of Performance: Pragmatic Breakdown in Veterans' Storytelling. In Diagnosing Folklore. Edited by Trevor J. Blank and Andrea Kitta. Jackson: University of Mississippi Press, pp. 215-32. 